\title{
Adapting health behavior measurement tools for cross-cultural use
}

\author{
Rachel C. Vreeman ${ }^{1,2,3^{*}}$, Megan S. McHenry ${ }^{1}$ and Winstone M. Nyandiko ${ }^{2,4}$ \\ *Correspondence: rvreeman@iupui.edu \\ 'Department of Pediatrics, Indiana University School of Medicine, Indianapolis, IN, USA. \\ 2USAID-Academic Model Providing Access to Healthcare (AMPATH) Partnership, Eldoret, Kenya. \\ ${ }^{3}$ The Regenstrief Institute, Inc., Indianapolis, IN, USA. \\ ${ }^{4}$ Department of Child Health and Paediatrics, Moi University School of Medicine, Eldoret, Kenya.
}

\begin{abstract}
Background: Addressing health disparities in the global community requires awareness of how cultural differences in beliefs, traditions, norms, and values shape health problems and behaviors.

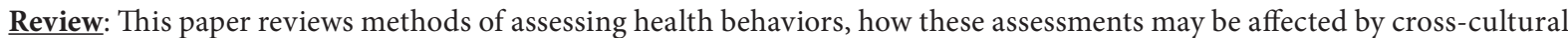
differences, and methods of adaptation of health behaviors across cultures. We describe the methods used in appropriate translation processes and pilot-testing for health behavior assessment tools. We also discuss ways to limit literacy demands and incorporate qualitative interviews.
\end{abstract}

Keywords: Cross-cultural comparison, health behaviors, outcomes assessments, evaluation methodology

\section{Introduction}

Many health indicators, such as mortality statistics, heights/ weights, and laboratory results, can be measured directly and quantitatively, other aspects of health, such as health behaviors, attitudes and motivations, cannot be measured directly. For example, beliefs about the causes of illness, fears of stigma or discrimination, or a family's sense of connectedness to the community may all influence the consistency with which they take medications, report depressive symptoms, or seek clinical care [1,2]. Measuring these relevant, but often hidden factors, may require the assembly of a selection of indicators to represent the health outcome. These indicators must reflect problems of social concern or core values of a culture shaping health behaviors [3].

Despite expanding work in cross-cultural health behavior research, few systematic approaches to the cross-cultural adaptation of health behavior measurement strategies and measurement tools exist. In systematic reviews on adherence to HIV therapy, for example, no existing measures had been validated in the resource-limited settings where the majority of the world's HIV-infected population lives [4,5]. Our objective is to summarize methods of assessing health behaviors, how cross-cultural differences may affect these assessments, and methods for adapting assessments across cultures.

\section{Review of cross-cultural adaptation for health behavior measures}

Methods of assessing health behaviors

Health behaviors can include preventive behaviors, illness behaviors taken when an individual perceives him-or herself to be ill, and sick-role behaviors undertaken for the purpose of getting well [6]. In a broad sense, health behavior refers not only to the actions taken related to health, but also to the determinants, correlates, and consequences of those actions [7]. Culturally determined factors, such as cultural diversity in the treatment of illness or in beliefs about the causes of sickness and health, are integral to health behaviors. These factors should also be considered when measuring health behaviors such as adhering to a medication regimen or seeking medical care [8].

Health behaviors can be assessed with either qualitative or quantitative methods. Qualitative methods of measurement strive to document and interpret what is being measured as fully as possible, in order to gather more broad, dynamic information from the participants [9]. For instance, researchers in Sudan used an ethnographic study with in-depth interviews to assess cultural perceptions and health behaviors related to safe motherhood for Sudanese women [10]. Qualitative measures of a health behavior typically involve open-ended questions or immersed observation of a phenomenon, [11] allowing for a more complete description of the measured behavior. In contrast, quantitative methods more narrowly measure the amount of a particular characteristic, emphasizing the measurement of objective, observable, and quantifiable data $[9,12]$. This method is useful to measure facts and causes of behavior that are assumed to be stable phenomena [13]. Examples of both are seen in (Table 1). Qualitative and quantitative methods have fundamentally different approaches, but they can be used in a complementary manner, also known as "mixed method approach" to give a more comprehensive perspective for a given outcome [4]. As an example, we used a mixed methods approach to evaluate 
Vreeman et al. Journal of Integrative Psychology and Therapeutics 2013,

http://www.hoajonline.com/journals/pdf/2054-4723-1-2.pdf

doi: $10.7243 / 2054-4723-1-2$

Table 1. Methodologies Used to Measure Health Behaviors [9].

\begin{tabular}{|c|c|}
\hline Quantitative & Qualitative \\
\hline Rating scales & $\begin{array}{l}\text { Interviews or focus group } \\
\text { discussions with the subjects } \\
\text { of interest }\end{array}$ \\
\hline Checklists & $\begin{array}{l}\text { Content analysis of documents } \\
\text { to identify common themes }\end{array}$ \\
\hline $\begin{array}{l}\text { Physiological measures (e.g., plasma drug } \\
\text { concentrations to measure medication } \\
\text { adherence) }\end{array}$ & Observation of participants \\
\hline $\begin{array}{l}\text { Observations or interviews in which } \\
\text { structured criteria are evaluated, } \\
\text { recorded, and quantified. }\end{array}$ & Open-ended questionnaires \\
\hline
\end{tabular}

factors associated with medication adherence and return to clinic for HIV-infected children after a period of conflict and violence in Kenya [14]. Qualitative key informant interviews allowed us to describe prominent barriers in the return to clinical care in the period immediately after the humanitarian crisis, while structured items evaluating missed medication doses and records of clinic attendance provided adherence and attendance rates.

In addition to considering the difference between qualitative and quantitative methods of measuring health behaviors, the language requirements of the measurement method merit consideration. Most methods of measuring a health behavior require the participants to use oral or written language, which becomes a key consideration in cross-cultural measurement. The basic cognitive processes involved in responding to a question--comprehending the question, remembering the information needed to answer the question, evaluating that information as shaped by one's attitudes and beliefs, and responding with an answer-are all influenced by both language and cultural context [15]. For example, when asking Kenyan families about children's HIV therapy adherence, cognitive interviewing revealed that they had difficulty comprehending key language concepts such as "missed doses" despite seemingly appropriate translation [16]. Among the measurement methods, verbal reports are generally simpler and less costly than formalized questionnaires or observations [3]. Verbal reports could include face-to-face interviews or the verbal reading of formal questionnaires or rating scales. The structure of interview or questionnaire items can vary in scope and formulation; some measurement items may be based on stories or vignettes, others use open-ended questions to elicit qualitative data, and still others employ closed-ended, quantitative questions. Many methods of assessing health behaviors require print literacy, involving reading and writing from the participants [17]. Examples include the use of written questionnaires, rating scales, surveys, or checklists. Sometimes, the literacy demands of these methodologies will be altered by the use of pictures instead of words, which require picture recognition as the form of symbolic representation [18]. A study in Burkina Faso, for example, evaluated self-reports of health through questionnaire items, a wooden representation of a visual analogue scale, and a visual analogue scale drawn on paper and found differences in cultural sensitivity [19].

Issues in cross-cultural measurement of health behaviors The need for cross-cultural measures of health behavior has become increasingly apparent. Health problems have global impact and there are dramatic health disparities both around the world and among subcultures of a given population $[20,9]$. With this increasing awareness has come more cross-cultural research, as well as a deeper understanding of how cultural differences in beliefs, traditions, norms, and values can shape health problems and behaviors [9]. In the earlier conceptual framework of empiricism, "culture-free" assessments made in a "context-free clinical setting" were considered the most reliable and valid for measuring health behavior [21]. Realizing that culture permeates all aspects of behavior has led to more "culture-common" assessments that try to measure behavior considered common among different cultures [18]. More recent work in cross-cultural measurement has recognized that a single assessment usually cannot be used universally in all cultures [22]. This requires attention to reducing cultural differences in how an assessment performs and adapting assessments for each culture, as the influence of culture will and should be detectable [21]. Some propose treating cultures as a variable under examination, similar to age or sex [23]. Cross-cultural administration of measurement tools often reveals particular cultural variables that need to be considered compared to the design and administration of the original assessment [24,25]. For example, in Stanczak's 2001 study looking at the development and validation of an Arabic version of the Expanded Trail Making Test, healthy Sudanese subjects had similar scores to American brain-damaged subjects when the adaptation of this neuropsychological test was used in "normal" US and Sudanese citizens, which is an unacceptable false positive diagnostic rate. Although the study was unable to provide a rationale for the significant differences, it did speculate on several hypotheses including differences in cognitive style which are influenced by sociocultural factors, the novelty of psychological testing, and possible developmental factors such as nutrition and educational opportunities [26].

Translation from one language into another is an obvious issue when one wants to measure something in multiple cultures; however, exchanging the words of one language for the words of another is not enough if the conceptual meaning is not equivalent [27]. Focusing solely on translating wordfor-word creates poor sentences. Even worse, translations sometimes lack comprehensible meaning-particularly if there are not equivalent words, parts of speech, or concepts within the target language [9]. Even when the same language is used from one country to another, there may be differences in the concepts elicited by a particular phrase [28]. A major issue to consider for measuring health behaviors across cultures is whether there is cultural equivalence for the concept being 
measured [29]. If conceptual equivalence is not present, a translated question may elicit a very different response from what was originally intended [18]. For example, if the meaning of depression varies from one culture to another, the assessment of health or behaviors related to depression in a given culture must take the meaning into account for both the measurement and for the interpretation of responses. For even better cultural equivalence, one would also have equivalence in how each cultural group operationalizes or defines the construct of interest. For example, good "quality of life" in one culture might include having material possessions such as a house and a car. In another culture, living near extended family or just having basic necessities available, such as food and water, might play an important role. Even with measurement instruments claiming to include items with validity across cultures, careful evaluation can uncover a lack of equivalence for concepts heavily influenced by the culture [30].

Biases affected by or related to one's culture may undermine the validity of an assessment of health behavior. Cultural biases could be present at the level of the construct, the method, or the individual measurement items being used [29]. To use a previous example, if one failed to understand that the close presence of family was important within a culture, measures of quality of life that never assessed family presence would not appropriately sample this construct. Then, this measure would have a construct bias undermining validity. Biases can also occur based on the methods used to measure in a behavior a particular culture. For example, the subcultures of Hispanic Americans and White Americans have been found to respond differently to measurement methods such as five-point rating scales, with Hispanics more often choosing the extreme responses [31]. Method bias can result if members of different cultural groups respond differently to a specific type of measurement instrument or method, such as different responses because of cultural differences in gender, age, educational level, or concern with maintaining social relationships. Cultural biases can also emerge at the level of an individual item or question used to measure a health behavior. Problems with item content, poor translation, or poorly formulated items can all bias how a particular culture responds $[29,32]$.

These biases and conceptual equivalence issues can create both subtle and significant problems in measuring a health behavior in a given culture. Even within the same culture, subculture differences in ethnicity, dialects or languages, gender, age, and education can impact the experience and results of health behavior measurements [33]. These challenges can be minimized by adapting health behavior assessments appropriately for use across cultures [34].

Adaptation of health behavior assessments across cultures Investigators seeking to measure health behavior across cultures often try to modify or adapt a particular measurement methodology to meet the challenges of cross-cultural assessment. If the reliability and validity of a strategy can be established in multiple cultures, this strengthens the evidence in favor of using it. However, the process of adaptation must overcome the challenges outlined previously. The majority of research on adapting health behavior assessments across cultures focuses on the adaptation of written questions, whether these questions to be used as part of a questionnaire, rating scale, or structured interview.

A careful approach to translation is crucial to cross-cultural adaptation of any strategy for assessing health behaviors. When developing a questionnaire or writing interview questions, simple steps can be followed to facilitate later translation (Table 2). Clear and objective wording is crucial when questions are translated. Chang's 2001 study on translation and the equivalence of questionnaires looked at the Menstrual Distress Questionnaire (MDS). Bilingual students were asked to complete Chinese and English versions of MDS and the kappa scores showed overall high equivalence. However, the few low kappa items contained subjective or colloquial Western terms that had been difficult to translate because the literal meanings in Chinese seemed strange [35]. For example, statements such as "feeling sad or blue" have caused difficulty in cross-cultural adaptation [36]. For any written materials, the reading level should be determined, with a goal of keeping it at the grade level of 6 or 7 by criteria such as the Flesch-Kincaid readability index, [17] as reading level adjustment may lessen other differences in cross-cultural performance [37]. Equivalent adaptations and simplifications should be considered for materials in other languages.

Table 2. Tested Recommendations for Developing Health Behavior Measures in English.

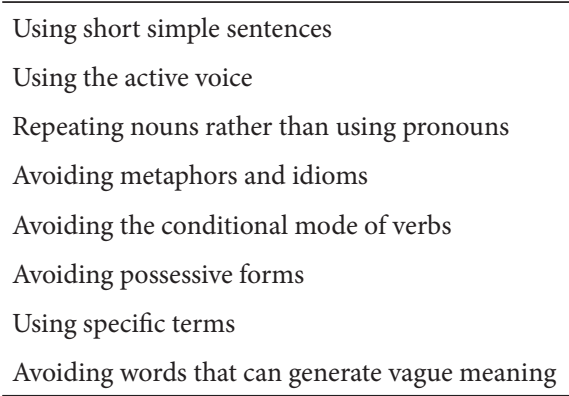

Cross-cultural research methods. New York: John Wiley and Sons; $1973[46]$.

The process of translation requires careful decisions among a number of processes. Appropriate translation employs methods far beyond simple language conversion; systematic evaluation of questionnaire translations reveal further evaluation is needed to ensure the language conversion maintains 
psychometric quality [38]. Translation should include frequency counts of words, aiming to translate words and expressions into words and expressions that occur with approximately the same frequencies in the two languages [39]. One must also decide whether to use unicentered (asymmetrical) translation or decentered (symmetrical) translation (Table 3). Whenever possible, decentered (symmetrical) translation is preferred as it prioritizes meaning equivalence. Decisions must also be made about whether to use a forward-translation design or a backtranslation design. The advantages and disadvantages of these

Table 3. Unicentered (Asymmetrical) vs Decentered (Symmetrical) Translation [9].

\begin{tabular}{ll}
\hline $\begin{array}{l}\text { Unicentered (Asymmetrical) } \\
\text { Translation }\end{array}$ & $\begin{array}{l}\text { Decentered (Asymmetrical) } \\
\text { Translation }\end{array}$ \\
\hline $\begin{array}{l}\text { Target language translation } \\
\text { follows or remains loyal to } \\
\text { source language. }\end{array}$ & $\begin{array}{l}\text { Both source and target languages } \\
\text { considered equally important. }\end{array}$ \\
$\begin{array}{l}\text { Often used when adapting } \\
\text { previously developed measure. }\end{array}$ & $\begin{array}{l}\text { Most easily implemented when } \\
\text { measurement tools for both cultures } \\
\text { are developed at same time. }\end{array}$ \\
$\begin{array}{l}\text { May hinder conceptual } \\
\text { equivalence. }\end{array}$ & $\begin{array}{l}\text { Improving meaning and meaning } \\
\text { equivalence are given priority for all } \\
\text { versions of measurement tool. }\end{array}$ \\
\hline
\end{tabular}

design strategies are noted in (Figure 1). The disadvantages mostly involve biases from translation. To minimize these biases, whenever possible, translators should be ethnically and culturally representative of the target population, but fluent in both the source and target language and familiar with both cultures [40]. The source language translators should also know and understand the construct being measured, while the target language translators would not have this familiarity or detailed knowledge [41].

Once translation has been carried out, the next important cross-cultural adaption step is pre-testing the translated instrument. Techniques for pre-testing health measurement instruments include cognitive interviewing, committee reviews, field-testing with bilinguals, and field-testing with monolinguals. Cognitive interviewing is a qualitative research technique to study how targeted audiences understand, mentally process, and respond to the materials presented, particularly for survey questionnaires [42]. Representatives from the target audience are asked to process the measurement items item-by-item, with a trained facilitator [43]. The facilitator uses verbal probing techniques and guided "thinking aloud" to evaluate how well the respondent understands the measurement items and what the questions

\section{Forward -translation strategy:}

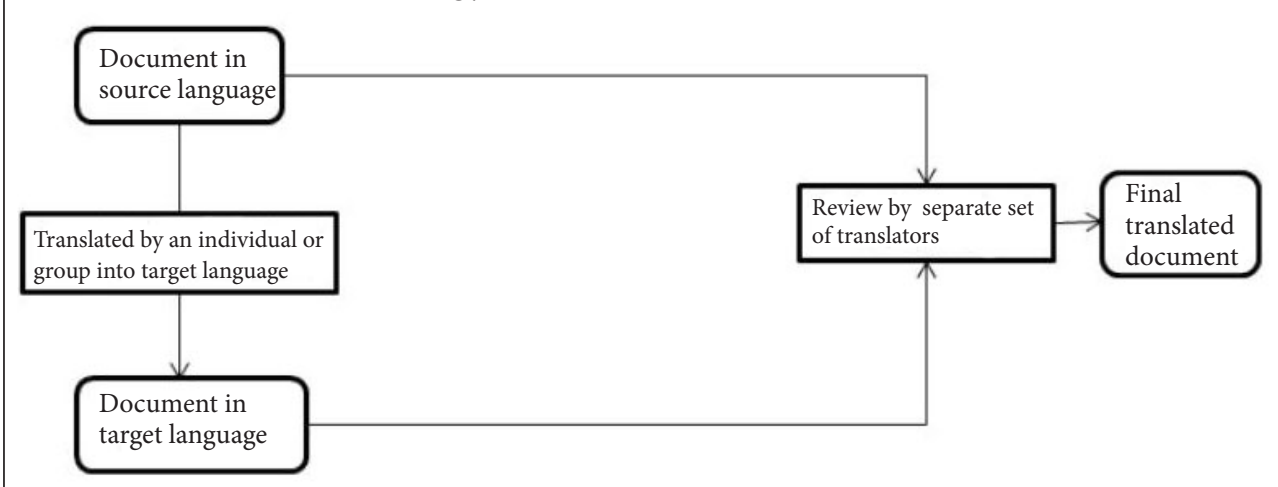

\begin{tabular}{|l|}
\hline Advantages: \\
\hline Those involved make direct \\
decision about the equivalence \\
of the source and target meterials \\
\hline Disadvantages: \\
\hline - Any biases inherent to the \\
translators themselves (whether \\
their education level, proficiency, \\
or grasp of the concepts) could \\
impact their decisions about \\
equivalence
\end{tabular}

\section{Back -translation strategy:}

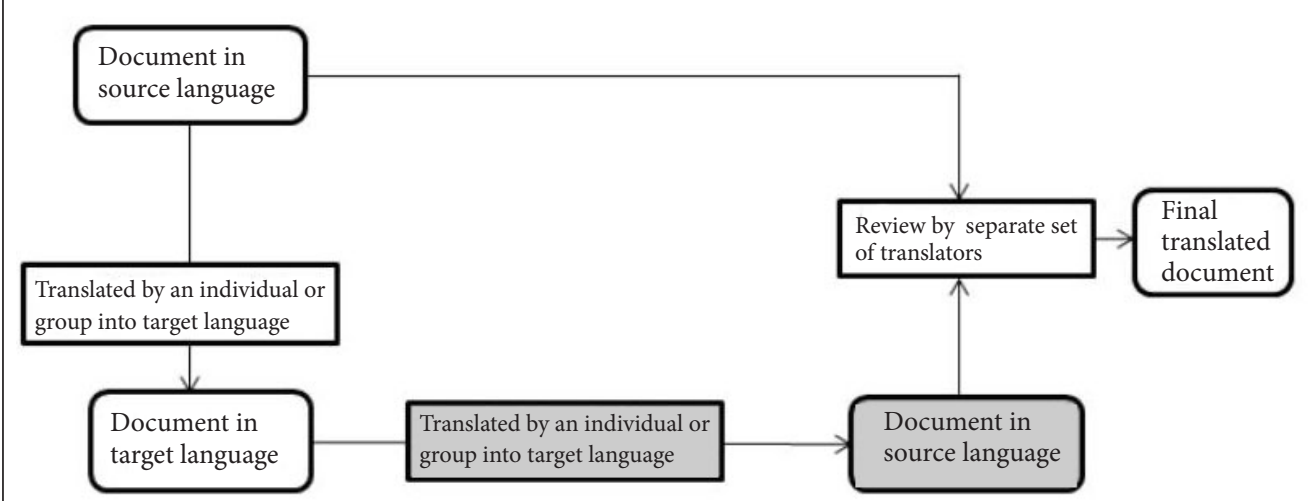

\begin{tabular}{|l|}
\hline Advantages: \\
\hline - $\begin{array}{l}\text { Provides a general assessment of } \\
\text { the quality of the translation }\end{array}$ \\
\hline Disadvantages: \\
\hline $\begin{array}{l}\text { May miss errors such as the use of } \\
\text { terms that would be completely } \\
\text { unfamiliar in the target language } \\
\text { and yet literally correct. }\end{array}$ \\
\hline
\end{tabular}

Figure 1. Design strategies for translation [39]. 
elicit in terms of their memories of relevant information, decision and judgment processes, and response processes [42]. We have used cognitive interviewing to pre-test and modify measures for patient adherence to medication and experiences of pain in Kenya [44,45]. A committee approach, with at least two experts reviewing the measures, can also be used to complement the cognitive interviewing or as another technique for pre-testing [9].

Field-testing the health measurement items with either bilingual or monolingual individuals provides another crucial step for evaluating reliability, validity, and equivalence. Fieldtesting with bilingual individuals uses a questionnaire or rating scale that exists in two languages to evaluate both language versions of the measurement tool. They can rate and compare each measurement item on the equivalence of the versions or the translation quality [39]. Monolingual individuals can complete both the original and back-translated versions of a measurement instrument to compare how each performs [39]. They can also complete the source language measurement, while simultaneously having target-language monolinguals complete the target language measurement. Items that perform differently in the two groups (and thus do not have item equivalence) can be identified and carefully studied [39].

\section{Recommendations for the adapting health behavior measurement tools for cross-cultural use}

In conclusion, assessing health behaviors in a cross-cultural setting requires careful attention to the choices of health behavior measurement methods, awareness of the challenges of cross-cultural health measurement, employment of the processes that can address these challenges, and an understanding of the culture of interest to guide the choices made at every stage. Following these methods to adapt measures to evaluate health behaviors in another culture are highlighted in this manuscript to maximize reliability and validity across cultures

\section{Key messages}

- When possible, assessment tools should be developed simultaneously in both source and target languages, following recommendations to use simple sentences.

- The best possible translation processes should be employed, including back-translation, decentering, committee involvement, and field-testing with bilingual speakers and monolingual speakers.

- Pilot-testing should investigate the cultural equivalence, reliability, and validity of any assessment tools and include representatives of the target population.

- Limiting literacy demands should be a priority. Pictures can be used in the place of written words, but pictures should be piloted for recognition prior to use.

Competing interests

The authors declare that they have no competing interests.

Authors' contributions
\begin{tabular}{|l|c|c|c|}
\hline Authors' contributions & RCV & MSM & WMN \\
\hline Research concept and design & $\checkmark$ & -- & $\checkmark$ \\
\hline Collection and/or assembly of data & $\checkmark$ & $\checkmark$ & -- \\
\hline Data analysis and interpretation & $\checkmark$ & $\checkmark$ & $\checkmark$ \\
\hline Writing the article & $\checkmark$ & $\checkmark$ & -- \\
\hline Critical revision of the article & $\checkmark$ & $\checkmark$ & $\checkmark$ \\
\hline Final approval of article & $\checkmark$ & $\checkmark$ & $\checkmark$ \\
\hline Statistical analysis & $\checkmark$ & -- & $\checkmark$ \\
\hline
\end{tabular}

\section{Acknowledgement}

This work was supported by a grant to Dr. Vreeman from the National Institute of Mental Health (5K23MH087225-03), as well as by the President's Emergency Plan for AIDS Relief (PEPFAR) through USAID under the terms of Cooperative Agreement No. AID-623-A-12-0001 It is made possible through joint support of the United States Agency for International Development (USAID). The contents of this paper are the sole responsibility of AMPATH and do not necessarily reflect the views of USAID or the United States Government.

\section{Publication history}

Editors: Carl Fulwiler, University of Massachusetts Medical School, USA.

Sara A. Jahnke, Institute for Biobehavioral Health Research, New York.

Received: 10-Oct-2013 Revised: 14-Nov-2013

Accepted: 03-Dec-2013 Published: 16-Dec-2013

\section{References}

1. Chia LR, Schlenk EA and Dunbar-Jacob J. Effect of personal and cultural beliefs on medication adherence in the elderly. Drugs Aging. 2006; 23:191-202. | Article | PubMed

2. Rao D, Kekwaletswe TC, Hosek S, Martinez J and Rodriguez F. Stigma and social barriers to medication adherence with urban youth living with HIV. AIDS Care. 2007; 19:28-33. | Article | PubMed

3. McDowell I. Measuring Health: A Guide to Rating Scales and Questionnaires. New York: Oxford University Press. 2006. I Pdf

4. Vreeman RC, Wiehe SE, Pearce EC and Nyandiko WM. A systematic review of pediatric adherence to antiretroviral therapy in low- and middle-income countries. Pediatr Infect Dis J. 2008; 27:686-91. | Article I PubMed

5. Simoni JM, Frick PA, Pantalone DW and Turner BJ. Antiretroviral adherence interventions: a review of current literature and ongoing studies. Top HIV Med. 2003; 11:185-98. | Pdf | PubMed

6. Kasl SV and Cobb S. Health behavior, illness behavior, and sick role behavior. I. Health and illness behavior. Arch Environ Health. 1966; 12:246-66. | Article | PubMed

7. Glanz K., B.K. Rimer and F.M. Lewis. Health Behavior and Health Education 3ed. Jossey-Bass: San Francisco, CA. 2002.

8. Sahay S, Reddy KS and Dhayarkar S. Optimizing adherence to antiretroviral therapy. Indian J Med Res. 2011; 134:835-49. | Article | PubMed Abstract | PubMed Full Text

9. Feher Waltz, C., O. Strickland and L. E. Measurement in Nursing and Health Research 3ed. New York: Springer Publishing Company. 2005.

10. Serizawa A, Ito K, Algaddal AH and Eltaybe RA. Cultural perceptions and health behaviors related to safe motherhood among village women in Eastern Sudan: Ethnographic study. Int I Nurs Stud. 2013. | Article | PubMed

11. Swanson W.C.J. From practice to grounded theory: Qualitative research 
in nursing. Menlo Park, CA: Addison-Wesley. 1986.

12. Duffy ME. Methodological triangulation: a vehicle for merging quantitative and qualitative research methods. Image J Nurs Sch. 1987; 19:130-3. | Article | PubMed

13. Stainback S. and W. Stainback. Broadening the research perspectives in special education. EXCEPTIONAL CHILDREN. 1984; 50:400-408. | Article

14. Vreeman RC, Nyandiko WM, Sang E, Musick BS, Braitstein $P$ and Wiehe SE. Impact of the Kenya post-election crisis on clinic attendance and medication adherence for HIV-infected children in western Kenya. Confl Health. 2009; 3:5. | Article | PubMed Abstract | PubMed Full Text

15. Tourangeau R. Cognitive science and survey methods: A cognitive perspective, in Cognitive aspects of survey design: Building a bridge between disciplines. T.S. Jabine, M; Tanur, J; and Tourangeau, R, Editor. 1984, National Academy Press: Washington, DC.

16. Vreeman RC, Nyandiko WM, Ayaya SO, Walumbe EG and Inui TS. Cognitive Interviewing for Cross-Cultural Adaptation of Pediatric Antiretroviral Therapy Adherence Measurement Items. Int J Behav Med. 2012. | Article | PubMed

17. Nielsen-Bohlman, L., A.M. Panzer and D.A. Kindig. Health Literacy: A Prescription to End Confusion. ed. B.o.N.a.B.H. Committee on Health Literacy. 2004, The National Academies Press: Washington D.C.

18. Carter JA, Lees JA, Murira GM, Gona J, Neville BG and Newton CR. Issues in the development of cross-cultural assessments of speech and language for children. Int J Lang Commun Disord. 2005; 40:385-401. | Article | PubMed

19. Blomstedt $Y$, Souares A, Niamba L, Sie A, Weinehall L and Sauerborn R. Measuring self-reported health in low-income countries: piloting three instruments in semi-rural Burkina Faso. Glob Health Action. 2012; 5. I Article | PubMed Abstract | PubMed Full Text

20. Michaud CM, Murray $\mathrm{CJ}$ and Bloom BR. Burden of disease--implications for future research. JAMA. 2001; 285:535-9. | Article | PubMed

21. Perez-Arce $P$. The influence of culture on cognition. Arch Clin Neuropsychol. 1999; 14:581-92. | Article | PubMed

22. Anastasi A. and S. Urbina. Psychological Testing 7th ed. Upper Saddle River, NJ: Prentice-Hall. 1997.

23. Eviatar Z. Culture and brain organization. Brain Cogn. 2000; 42:50-2. Article | PubMed

24. Stanczak DE, Stanczak EM and Awadalla AW. Development and initial validation of an Arabic version of the Expanded Trail Making Test: implications for cross-cultural assessment. Arch Clin Neuropsychol. 2001; 16:141-9. | Article | PubMed

25. Boivin MJ. The effect of culture on a visual-spatial memory task. J Gen Psychol. 1991; 118:327-34. | Article | PubMed

26. Stanczak DE, Stanczak EM and Awadalla AW. Development and initial validation of an Arabic version of the Expanded Trail Making Test: implications for cross-cultural assessment. Arch Clin Neuropsychol. 2001; 16:141-9. | Article | PubMed

27. Khalaila R. Translation of questionnaires into Arabic in cross-cultural research: techniques and equivalence issues. J Transcult Nurs. 2013; 24:363-70. | Article | PubMed

28. Kassin M, De Castro F, Arango I and Goth K. Psychometric properties of a culture-adapted Spanish version of AIDA (Assessment of Identity Development in Adolescence) in Mexico. Child Adolesc Psychiatry Ment Health. 2013; 7:25. | Article | PubMed Abstract | PubMed Full Text

29. Van de Vijver F.J.R. and Y.H. Poortinga. Towards an integrated analysis of bias in cross-cultural assessment. European Journal of Psychological Assessment. 1997; 13:21-29. | Pdf

30. Bowden A and Fox-Rushby JA. A systematic and critical review of the process of translation and adaptation of generic health-related quality of life measures in Africa, Asia, Eastern Europe, the Middle East, South America. Soc Sci Med. 2003; 57:1289-306. | Article | PubMed

31. Hui C.H. and H.C. Triandus. Effects of culture and response format on extreme response style. Journal of Cross-Culture Psychology. 1989; 20: 296-309. | Article

32. Maters GA, Sanderman R, Kim AY and Coyne JC. Problems in cross- cultural use of the hospital anxiety and depression scale: "no butterflies in the desert". PLoS One. 2013; 8:e70975. | Article | PubMed Abstract | PubMed Full Text

33. Gonzalez JM, Rubin M, Fredrick MM and Velligan DI. A qualitative assessment of cross-cultural adaptation of intermediate measures for schizophrenia in multisite international studies. Psychiatry Res. 2013; 206:166-72. | Article | PubMed

34. Willis G. and K. Miller. Cross-Cultural Cognitive Interviewing: Seeking Comparability and Enhancing Understanding. Field Methods. 2011. Article

35. Chang AM, Chau JP and Holroyd E. Translation of questionnaires and issues of equivalence. J Adv Nurs. 1999; 29:316-22. | Article | PubMed

36. Kleinman A. Anthropology and psychiatry. The role of culture in crosscultural research on illness. BrJ Psychiatry. 1987; 151:447-54. | Article | PubMed

37. Manly JJ, Jacobs DM, Touradji P, Small SA and Stern Y. Reading level attenuates differences in neuropsychological test performance between African American and White elders. J Int Neuropsychol Soc. 2002; 8:3418. | Article | PubMed

38. Puga VO, Lopes AD and Costa LO. Assessment of cross-cultural adaptations and measurement properties of self-report outcome measures relevant to shoulder disability in Portuguese: a systematic review. Rev Bras Fisioter. 2012; 16:85-93. | Article | PubMed

39. Hambleton R.K, P.F. Merenda and C.D. Spielberger. Eds Adapting Educational and Psychological Tests for Cross-Cultural Assessment. Lawrence Erlbaum Associates: Mahwah, New Jersey. 2005.

40. Roberts G, Roberts S, Tranter R, Whitaker R, Bedson E, Tranter S, Prys $D$, Owen $\mathrm{H}$ and Sylvestre $\mathrm{Y}$. Enhancing rigour in the validation of patient reported outcome measures (PROMs): bridging linguistic and psychometric testing. Health Qual Life Outcomes. 2012; 10:64. | Article | PubMed Abstract | PubMed Full Text

41. Geisinger K.F. Cross-cultural normative assessment: Translation and adaptation issues influencing the normative interpretation of assessment instruments. Psychological Assessment. 1994; 6:304-312. Article

42. Willis G.B. Cognitive Interviewing: A tool for improving questionnaire design. Thousand Oaks, CA: Sage Publications. 2005.

43. DeMaio T.J, B. Rothgeb and J. Hess. Improving survey quality through pretesting, in Working Papers in Survey Methodology, U.S. Census Bureau. Washington, D.C. 1998. | Pdf

44. Huang KT, Owino C, Vreeman RC, Hagembe M, Njuguna F, Strother RM and Gramelspacher GP. Assessment of the face validity of two pain scales in Kenya: a validation study using cognitive interviewing. $B M C$ Palliat Care. 2012; 11:5. | Article | PubMed Abstract | PubMed Full Text

45. Vreeman RC, Nyandiko WM, Ayaya SO, Walumbe EG and Inui TS. Cognitive Interviewing for Cross-Cultural Adaptation of Pediatric Antiretroviral Therapy Adherence Measurement Items. Int I Behav Med. 2012. | Article | PubMed

46. Brislin RW, Lonner WJ and Thorndike RM. Cross-cultural research methods. New York: John Wiley and Sons. 1973.

\section{Citation:}

Vreeman RC, McHenry MS and Nyandiko WM. Adapting health behavior measurement tools for cross-cultural use. J Integr Psychol Ther. 2013; 1:2. http://dx.doi.org/10.7243/2054-4723-1-2 